\title{
Aging impairs the angiogenic response to ischemic injury and the activity of implanted cells: Combined consequences for cell therapy in older recipients
}

\author{
Yufeng Zhuo, MD, ${ }^{\mathrm{a}, \mathrm{b}}$ Shu-Hong Li, MD, MSc, ${ }^{\mathrm{a}}$ Min-Sheng Chen, MD, ${ }^{\mathrm{b}}$ Jun Wu, MD, ${ }^{\mathrm{a}}$ \\ Heather Y. McDonald Kinkaid, MSc, ${ }^{a}$ Shafie Fazel, MD, PhD, ${ }^{a}$ Richard D. Weisel, MD, ${ }^{\mathrm{a}, *}$ and \\ Ren-Ke Li, MD, $\mathrm{PhD}^{\mathrm{a}, *}$
}

\begin{abstract}
Objective: Cell therapy has received much attention for its potential to regenerate ischemic organs, but initial clinical trials in aged patients did not replicate the dramatic benefits recorded in preclinical studies with young animals. This study was designed to improve our understanding of age-related changes in the response to ischemic injury and the regenerative capacity of implanted cells in the context of cell therapy for older recipients.
\end{abstract}

\begin{abstract}
Methods and Results: Restoration of regional perfusion after hind limb femoral artery ligation was impaired $(P<.05)$ in old (vs young) rats, reflecting approximately $50 \%$ reductions in circulating endothelial progenitor cells and the release of vascular endothelial growth factor/basic fibroblast growth factor. Bone marrow stromal cells from young or old donors implanted into the ischemic hind limbs of young or old rats restored regional perfusion. Specifically, we documented significantly greater $(P<.05)$ angiogenic potential in young (vs old) donor cells when recipient age was controlled and greater $(P<.05)$ regenerative responses in young (vs old) recipients when donor cell age was controlled. Contributing to these differences were significantly greater survival in young (vs old) donor cells (in vitro and after implantation) and about 2-fold more production of vascular endothelial growth factor/basic fibroblast growth factor and mobilization of endogenous endothelial progenitor cells in young (vs old) rats in response to ischemia.
\end{abstract}

Conclusions: The outcome of cell therapy in older recipients is determined by a combination of age effects on the donor cells and on the recipients' endogenous responses. Donor cell age and recipient age are equally important contributors to the outcome of cell therapy; thus, novel biointerventions will need to target both components of the process. (J Thorac Cardiovasc Surg 2010;139:1286-94)

\section{Supplemental material is available online.}

Autologous bone marrow or blood cells can promote neovascularization, which facilitates regeneration and helps to restore function within ischemic tissues. ${ }^{1-4}$ Principal among the potential mechanisms responsible for these responses is

From the Division of Cardiovascular Surgery and Department of Surgery, ${ }^{\text {a }}$ Toronto General Research Institute and University of Toronto, Toronto, Ontario, Canada, and the Department of Cardiology, ${ }^{\mathrm{b}}$ The Second Affiliated Hospital of Guangzhou Medical College, Guangzhou, China.

Disclosures: Financial support was provided by grants to R.-K.L. from the Canadian Institutes of Health Research (MOP14795) and Eileen Mercier and ING Canada Inc and to R.W. from the Heart and Stroke Foundation of Ontario (T5809, T6148). R.-K.L. is a Career Investigator of the Heart and Stroke Foundation of Canada and holds a Canada Research Chair in cardiac regeneration.

Dr Zhuo's current affiliation is Panyu He Xian Memorial Hospital, Guangzhou, China.

* R.D.W. and R.-K.L. contributed equally as co-corresponding authors of this manuscript.

Received for publication June 18, 2009; revisions received Aug 6, 2009; accepted for publication Aug 26, 2009; available ahead of print Nov 20, 2009.

Address for reprints: Ren-Ke Li, MD, PhD, Department of Surgery, Division of Cardiovascular Surgery, Toronto General Research Institute, MaRS Centre, Toronto Medical Discovery Tower, Room 3-702, 101 College St, Toronto, ON, Canada M5G 1L7 (E-mail: renkeli@uhnres.utoronto.ca).

$0022-5223 / \$ 36.00$

Copyright (C) 2010 by The American Association for Thoracic Surgery doi:10.1016/j.jtcvs.2009.08.052 the paracrine amplification of endogenous repair processes. Encouraging results from the preclinical studies rapidly sparked clinical trials in which autologous cells were implanted into infarcted myocardium to boost functional regeneration. ${ }^{5}$ Unfortunately, the early results in patients were less promising than predicted: for example, a meta-analysis of 10 recent clinical trials found cardiac ejection fraction improved by only $3 \%$ when cells were infused after a myocardial infarction. ${ }^{6}$ Notably, most preclinical studies were performed in healthy, young animals, whereas the clinical trials enrolled patients of advanced age with multiple comorbidities. Previous studies have extensively documented diminished function in aged cells ${ }^{7-12}$; other reports suggest that the aged cell recipient has a limited healing response (including an attenuated bone marrow response to ischemia). ${ }^{13}$ The implication is that improving the outcome of cell therapy in older patients will require addressing both donor cell functioning and recipient responsiveness. However, before the next generation of biointerventions can be designed, a better understanding is required of the multiple effects of aginga main confounder in studies of autologous cell transplantation. Here, as a first step toward predicting which approach will best enhance future clinical cell therapy trials, we investigate the combined effects of aging on donor cells and recipients of cell therapy in a rat model of hind limb ischemia. 


$$
\begin{aligned}
& \text { Abbreviations and Acronyms } \\
& \begin{aligned}
\text { ANOVA } & =\text { analysis of variance } \\
\text { bFGF } & =\text { basic fibroblast growth factor } \\
\text { BMSC } & =\text { bone marrow stromal cell } \\
\text { BrdU } & =\text { bromodeoxyuridine } \\
\text { ELISA } & =\text { enzyme-linked immunosorbent assay } \\
\text { EPC } & =\text { endothelial progenitor cell } \\
\text { FITC } & =\text { fluorescein isothiocyanate } \\
\text { LDPI } & =\text { laser Doppler perfusion image } \\
\text { TUNEL } & =\text { terminal dUTP nick-end labeling } \\
\text { VEGF } & =\text { vascular endothelial growth factor }
\end{aligned}
\end{aligned}
$$

\section{MATERIALS AND METHODS}

\section{Animals}

We used female Lewis rats (young $=6-8$ weeks; old $=60-64$ weeks; Harlan Sprague Dawley, Inc, Indianapolis, Ind). Animal procedures were approved by the Animal Care Committee of the University Health Network, and all animals received humane care in compliance with the "Guide for the Care and Use of Laboratory Animals"' (NIH No. 85-23, revised 1996).

\section{Isolation, Expansion, and Characterization of Bone Marrow Cells}

Bone marrow stromal cells (BMSCs) were obtained from young or old rats as described previously. ${ }^{4}$ Isolated cells were cultured, expanded ( 3 passages), and characterized by flow cytometry, ${ }^{2}$ as detailed in the online E-Materials and Methods section.

\section{Hind Limb Ischemia and Cell Transplantation}

Ischemia was established in the right hind limbs of young and old rats, as described previously ${ }^{1}$ and in the online E-Materials and Methods section. Left hind limbs served as nonischemic controls.

Young and old rats were randomized into the following 6 groups $(\mathrm{n}=8-$ 10 rats per group): young or old recipients of culture medium only ( $\mathrm{Y}$ control, O control), young or old recipients of cells isolated from young donors (Y-Y, Y-O), and young or old recipients of cells isolated from old donors $(\mathrm{O}-\mathrm{Y}, \mathrm{O}-\mathrm{O})$. One day after hind limb ischemia was established, cells $(5 \times$ $10^{6}$ BMSCs total in $0.3 \mathrm{~mL}$ phosphate-buffered saline solution) or culture medium (control groups) were delivered by 5 separate injections into the ischemic right thigh muscle.

\section{Hind Limb Blood Perfusion}

Perfusion in the hind limbs was measured with a laser Doppler perfusion image (LDPI) analyzer (PeriScan PIM 3 Systems; Perimed AB, Järfälla Sweden), as described in the online E-Materials and Methods section, at 5 time points: before ischemia (day 0 ); immediately before cell transplantation (day 1 after ischemia); and days 7, 14, and 21 after transplantation. The LDPI index was calculated as the ratio of perfusion in the ischemic versus the nonischemic hind limb. ${ }^{1}$

\section{Calf Muscle Weight Loss}

At 21 days after transplantation, calf muscles were harvested ( $n=8$ per group) and weighed. Loss of mass in the ischemic muscle was expressed as the percent decrease in mass relative to the nonischemic (left) calf muscle.

\section{Capillary and Arteriolar Densities in Ischemic Tissue}

At 21 days after transplantation, capillary densities (ratio of capillaries/ muscle fibers) and arteriolar densities (average number of arteriole rings per high-power field) were quantified in stained or immunostained cryosections from the ischemic hind limb muscles ( $\mathrm{n}=4$ per group), as described in the online E-Materials and Methods section.

\section{In Vitro Donor Cell Apoptosis}

BMSCs $\left(3 \times 10^{5}\right)$ isolated from young $(n=6)$ or old $(n=6)$ donor rats were cultured in a hypoxic environment for 24 hours, as detailed in the online E-Materials and Methods section. Apoptotic cells were detected by a terminal dUTP nick-end labeling assay (TUNEL; Roche Diagnostics, Indianapolis, Ind) according to the manufacturer's instructions, and counted in 3 randomly selected fields per well by 2 blinded investigators. TUNEL-positive cell counts were expressed as a percentage of total cells.

\section{In Vivo Implanted Cell Survival}

Donor BMSCs labeled with bromodeoxyuridine (BrdU, Sigma Chemical Co, St Louis, Mo) before implantation were identified immunohistochemically in the ischemic tissue at 21 days after transplantation and quantified in 5 randomly selected fields per formalin-fixed tissue section $(\mathrm{n}=10$ per group) as described in the online E-Materials and Methods section. Implanted cell survival was expressed as the average number of BrdUpositive nuclei per $0.2 \mathrm{~mm}^{2}$.

\section{In Vitro and In Vivo Vascular Endothelial Growth Factor (VEGF) and Basic Fibroblast Growth Factor (bFGF) Protein Expression}

BMSCs $\left(3 \times 10^{5}\right)$ from young or old donors $(\mathrm{n}=6$ per group) were cultured in 24-well plates with serum-free medium, or incubated in a hypoxic environment with serum-free medium for 24 hours. Conditioned medium was collected, and VEGF and bFGF expression levels (expressed as picograms per milligram total protein) were measured with enzyme-linked immunosorbent assay (ELISA) kits (Quantikine; R\&D Systems, Inc, Minneapolis, Minn).

Muscle samples ( $\mathrm{n}=6$ per group) were harvested from the ischemic hind limbs of young and old rats at 7 days after cell transplantation, as described in the online E-Materials and Methods section. VEGF and bFGF levels were measured with the ELISA kits.

\section{Endothelial Progenitor Cell (EPC) Mobilization}

EPC-like mononuclear cells were quantified in peripheral blood and spleen at 7 days after cell transplantation in young and old rats (and before ischemia in $\mathrm{Y}$ control and $\mathrm{O}$ control; $\mathrm{n}=5$ per group) as described in the online E-Materials and Methods section. EPCs were identified by flow cytometry as $\mathrm{CD} 34^{+} / \mathrm{KDR}^{+}$cells. ${ }^{14,15}$

\section{Statistical Analyses}

Data are expressed as mean $\pm \mathrm{SD}$. Analyses were performed with GraphPad Prism 4 software (San Diego, Calif). Comparisons between 2 age groups with respect to muscle loss and capillary and arteriolar densities in young and old rats, BrdU+ and TUNEL+ cells counts, and in vitro growth factor levels were carried out with unpaired, 2-tailed, unequal variance Student $t$ tests. Two-way analyses of variance (ANOVA) tested the main and interactive effects of age and time after ischemia on LDPI or EPC recruitment. When F values were significant, Bonferroni post-hoc tests were applied to specify significant differences among the groups. One-way ANOVAs compared all groups studied with respect to LDPI, capillary and arteriolar densities, or muscle loss at 21 days after cell implantation, or growth factor levels and EPC recruitment at 7 days after implantation. When $F$ values were significant, Neuman-Keuls posthoc tests were applied to specify significant differences among the groups. Correlation analyses were performed on the basis of group mean values. 


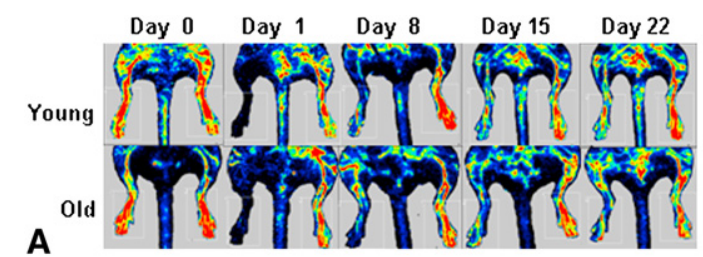

A
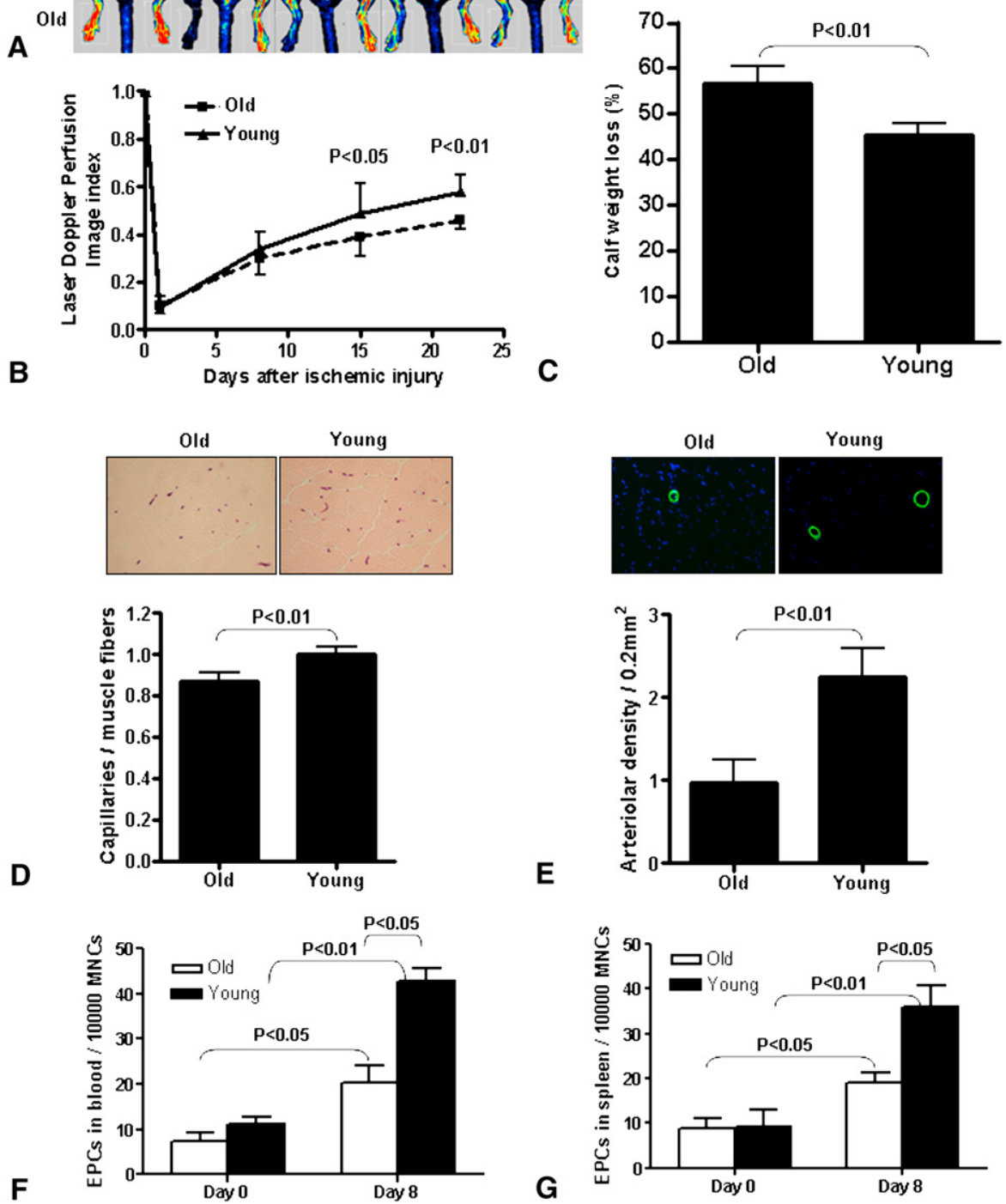

$\mathbf{E}$

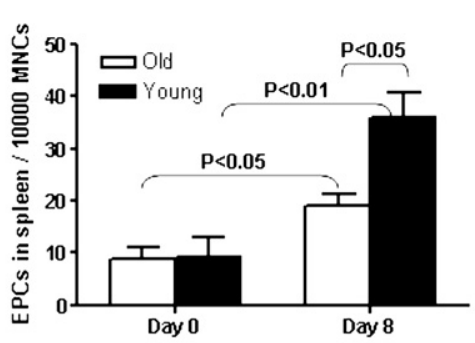

FIGURE 1. Angiogenic recovery after hind limb ischemia in young and old rats. A, Representative laser Doppler perfusion images (LDPI) taken in young and old rats (Young, Old) over 22 days after surgically induced right hind limb ischemia (no cell or media treatment). B, Recovery of blood flow in the ischemic limbs of young and old rats (ratio of perfusion in the ischemic to normal limb, or LDPI index; $\mathrm{n}=10$ per group). $\mathrm{F}=3.43, P<.05$. $P$ values indicate significant differences between age groups at time points indicated. $\mathrm{C}$, Calf muscle weight loss (expressed as percent decrease in mass relative to the nonischemic calf muscle) in young and old rats at 22 days after ischemic injury ( $n=8$ per group). $D$, Representative micrographs (magnification $=200 \times$ ) illustrating capillaries (purple $=$ alkaline phosphatase staining) in the ischemic hind limb muscle of young and old rats 22 days after injury; graph quantifying capillary density (ratio of capillaries to muscle fibers; $\mathrm{n}=4$ per group). $\mathrm{E}$, Representative micrographs (magnification $=200 \times$ ) illustrating arterioles (green $=\alpha$-smooth muscle actin staining) in the ischemic tissue of young and old rats at 22 days after injury; graph quantifying arteriolar density (per $0.2 \mathrm{~mm}^{2} ; \mathrm{n}=4$ per group). $\mathrm{F}$ and $\mathrm{G}$, Number of endothelial progenitor cells (EPCs; per 10,000 mononuclear cells $[M N C s])$ in peripheral blood $(\mathrm{F}=48.48, P<.001 ; \mathrm{F})$ and spleen $(\mathrm{F}$ $=26.06, P<.001 ; \mathrm{G}$ ) of young and old rats on days 0 and 8 after ischemic injury ( $\mathrm{n}=5$ per group).

\section{RESULTS}

\section{Aging Impairs Angiogenesis in Response to Ischemia}

To quantify the effect of age on tissue revascularization after an ischemic insult, we generated hind limb ischemia in young and old rats. In both age groups, ischemic hind limb perfusion (LDPI) decreased by $90 \%$ at 1 day after arterial ligation. Recovery of regional perfusion over the following 21 days was significantly more rapid in young compared with old rats (Figure 1, $A$ and $B$ ), and calf weight loss was significantly attenuated (Figure 1,C). Within the ischemic 

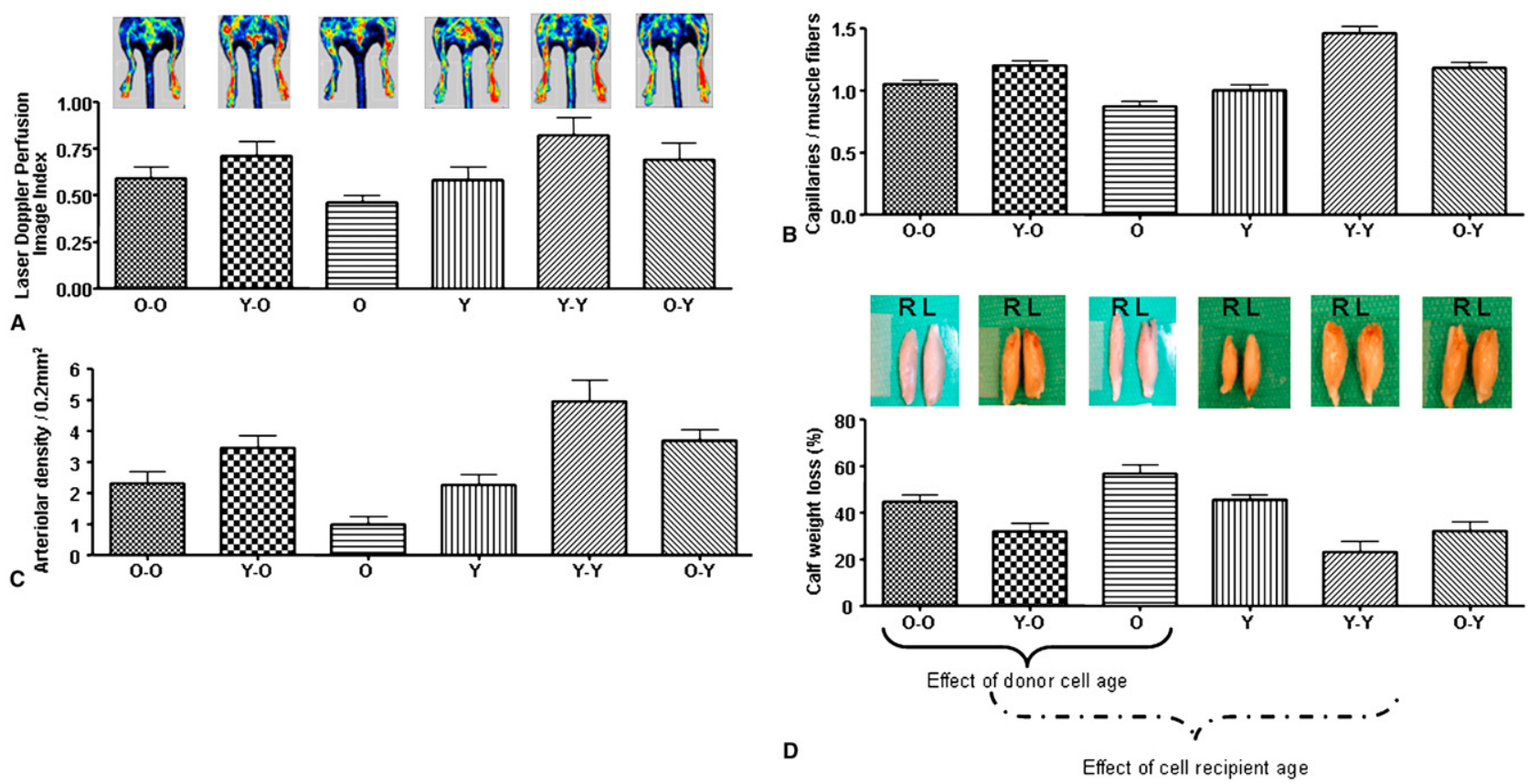

FIGURE 2. Angiogenic recovery after cell therapy. A, Representative laser Doppler perfusion images (LDPI) taken over 22 days after surgically induced right hind limb ischemia; graph quantifying LDPI index at 21 days after cell implantation ( $\mathrm{n}=8-10$ per group). B and C, Capillary density (capillaries/muscle fibers; B) and arteriolar density (per $0.2 \mathrm{~mm}^{2} ; \mathrm{C}$ ) in the ischemic hind limb at 21 days after cell implantation ( $\mathrm{n}=4$ per group). D, Representative images illustrating calf muscles from the right $(R$; ischemic) and left ( $L$; nonischemic) hind limbs of a single rat at 21 days after cell implantation; graph quantifying calf muscle weight loss (expressed as percent decrease in mass relative to the nonischemic calf muscle; $\mathrm{n}=8$ per group). All measurements were performed in the following groups: young or old recipients of culture medium only $(Y, O)$, young or old recipients of bone marrow stromal cells (BMSCs) isolated from young donors $(Y-Y$, $Y-O)$, and young or old recipients of BMSCs isolated from old donors $(O-Y, O-O)$. Brackets at base identify the groups involved in the 2 major comparisons: recipient age was controlled to study the effect of donor cell age (solid bracket); donor cell age was controlled to study the effect of cell recipient age (broken bracket). In parts A to D, ANOVA $(\mathrm{F}=28.47,=421.3,=217.5,=94.81$, respectively; all $P<.001)$ followed by Neuman-Keuls post-hoc tests indicated significant differences $(P<.05)$ for all group comparisons, with the following exceptions: O-O did not differ from Y, and Y-O did not differ from O-Y $(P>.05)$.

tissue, capillary density was 1.2-fold greater (Figure 1, D), and arteriolar density (assessed with $\alpha$-smooth muscle actin immunostaining) was 2.3-fold greater (Figure 1,E) in young compared with old animals (all measures $P<.05$ ). To identify factors responsible for these age-related differences in the angiogenic response to ischemia, we quantified EPCs and levels of angiogenic factors in both groups. Before ischemia, young and old rats exhibited similar numbers of EPCs in the circulation and the spleen (Figure 1, $F$ and $G$ ). Eight days after ischemia, EPC numbers increased significantly $(P<$ $.05)$ in both age groups, but the response produced twice as many EPCs in the young rats $(P<.05$; Figure $1, F$ and $G)$. Similarly, VEGF and bFGF levels were 1.9- and 2.1-fold higher, respectively, in the ischemic tissue of young compared with old rats (see Figure 3, $A$ and $B$ ).

\section{The Angiogenic Potential of Cell Therapy Is Diminished by Older Donor Cells}

To isolate the role of donor cell age from that of recipient age in the outcome of cell therapy in a clinically relevant model, we compared the angiogenic responses in old recipients of BMSCs isolated from young or old donors.
Donor cell age did not affect BMSC phenotype: by flow cytometry, more than $95 \%$ of all cells expressed CD29 and CD90.1, whereas less than 2\% expressed CD34 and CD45 (data not shown). However, old (compared with young) donor cells were associated with significantly lower regional perfusion (Figure 2, $A$ ) and capillary (Figure 2, B) and arteriolar (Figure 2,C) densities in the old recipients at 21 days after implantation, as well as significantly greater calf weight loss (Figure 2,D) (reductions of up to $25 \%$; all measures $P<.01$ ), although old donor cells did produce significant $(P<.01)$ improvements on each of these variables compared with medium ( $\mathrm{O}$ control).

Angiogenic factor production and endogenous stem cell homing were also reduced with the implantation of old (vs young) cells. At 7 days after transplantation, increases (relative to $\mathrm{O}$ control) in both VEGF and bFGF levels within the ischemic tissue of old recipients were doubled when the donor cells were derived from young rather than old donors (Figure 3, $A$ and $B$ ). Increases in endogenous EPC counts in the blood and spleen were approximately 1.6fold higher after implantation with young (vs old) cells (Figure 3, $C$ and $D$ ) (all measures $P<.01$ ). 

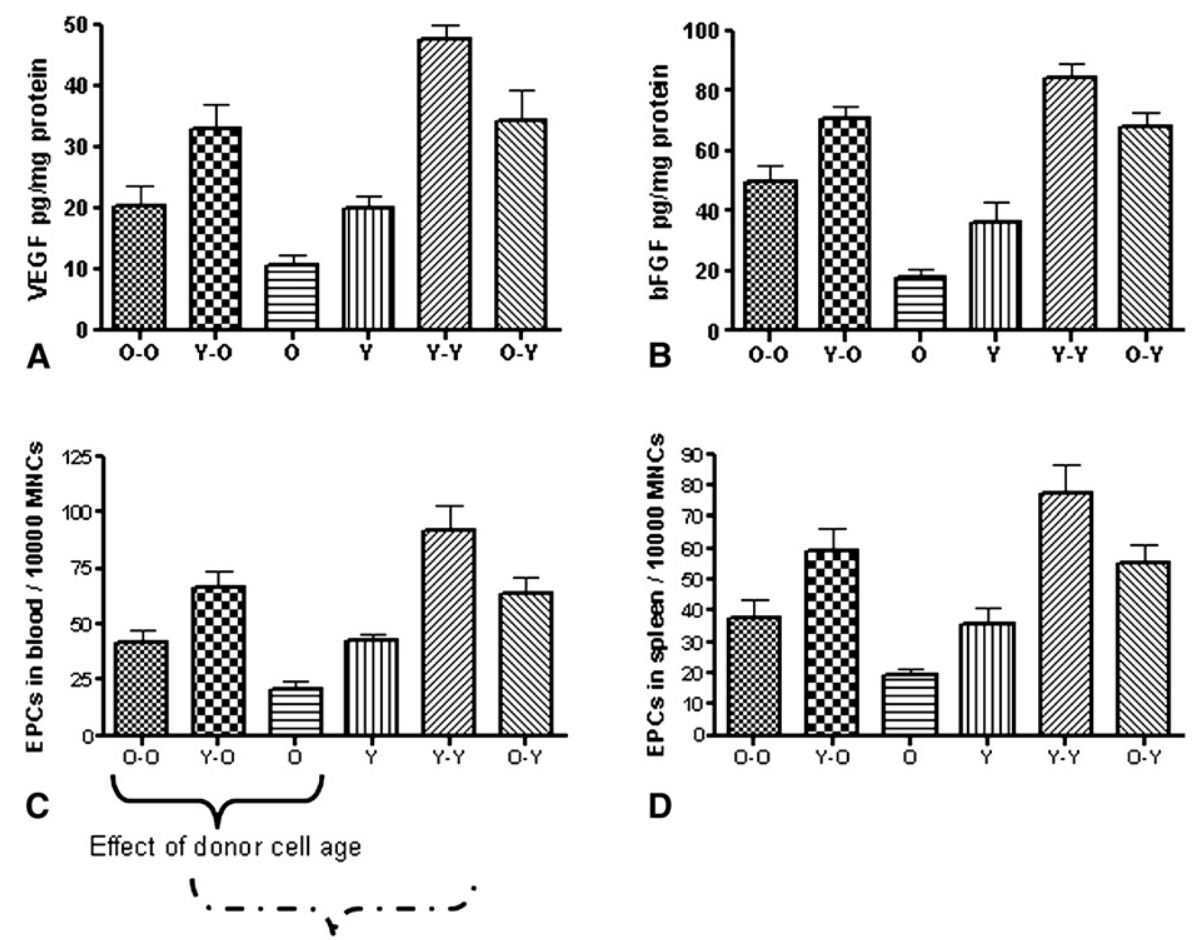

Effect of cell recipient age

FIGURE 3. Factors affecting angiogenic recovery after cell therapy. A and $\mathrm{B}$, Levels of vascular endothelial growth factor (VEGF; A) and basic fibroblast growth factor $(b F G F ; \mathrm{B})$ in the ischemic hind limb muscle at 7 days after cell implantation ( $\mathrm{n}=6$ per group). $\mathrm{C}$ and $\mathrm{D}$, Number of endothelial progenitor cells (EPCs; per 10,000 mononuclear cells [MNCs]) in peripheral blood (C) and spleen (D) at 7 days after cell implantation ( $\mathrm{n}=5$ per group). All measurements were performed in the following groups: young or old recipients of culture medium only $(Y, O)$, young or old recipients of bone marrow stromal cells (BMSCs) isolated from young donors $(Y-Y, Y-O)$, and young or old recipients of BMSCs isolated from old donors $(O-Y, O-O)$. Brackets in part C identify the groups involved in the 2 major comparisons: recipient age was controlled to study the effect of donor cell age (solid bracket); donor cell age was controlled to study the effect of cell recipient age (broken bracket). In parts A to D), ANOVA $(\mathrm{F}=148.4,=233.7,=60.29,=59.34$, respectively; all $P<.001)$ followed by Neuman-Keuls post-hoc tests indicated significant differences $(P<.01)$ for all group comparisons, with the following exceptions: O-O did not differ from $\mathrm{Y}$, and Y-O did not differ from O-Y $(P>.05)$.

We also found that implanted cell survival was reduced with old (vs young) donor cells. Twenty-one days after cell transplantation, $50 \%$ more young than old BrdU pre-labeled BMSCs were identified within the ischemic tissue of old recipients $(P<.01$; Figure $4, A)$, whereas no BrdU-positive cells were identified in the $\mathrm{O}$ control tissue. To investigate the mechanisms underlying these differences, we tested the stress responses of young and old donor cells in vitro. After a 24-hour incubation in a hypoxic environment with serum-free medium, BMSCs from old donors were 2.1 times more susceptible to apoptosis (TUNEL) than those from young donors $(P<.01$; Figure $4, B)$. Hypoxic cells from both age groups released more angiogenic cytokines than age-matched, nonhypoxic control cells; however, young hypoxic cells secreted an average of $70 \%$ more VEGF and bFGF than old hypoxic cells $(P<.05$; Figure $4, C$ and $D)$.

\section{The Angiogenic Response to Cell Therapy Is Diminished in Older Recipients}

To isolate the role of recipient age from that of donor cell age in the outcome of cell therapy, we compared the angio- genic responses in young and old recipients of BMSCs isolated from young donors.

At 21 days after cell implantation, both young and old cell recipients exhibited significant and similar increases in regional perfusion, blood vessel (capillary and arteriolar) densities, and calf muscle preservation relative to age-matched (medium injected) controls (average increases of $45 \%, 41 \%$, $186 \%$, and $87 \%$, respectively; $P<.01$; Figure 2), indicating that the magnitude of the angiogenic response to cell therapy was similar in young and old recipients. But importantly, as discussed previously, all 4 measures were significantly $(P<.05)$ depressed in the old recipients of medium (O controls) compared with Y controls. Consequently, the absolute LDPI (Figure 2, $A$ ) and capillary and arteriolar densities (Figure 2, $B$ and $C$ ) were significantly greater in young compared with old recipients of BMSCs $(15 \%, 22 \%$, and $43 \%$ higher, respectively), and the absolute percentage weight loss was reduced by $38 \%$ in the ischemic limbs of young compared with old cell recipients (Figure 2,D) (all measures $P<.01$ ).

We observed the same pattern of higher VEGF and bFGF levels (44\% and 19\% higher, respectively; Figure 3, $A$ and 

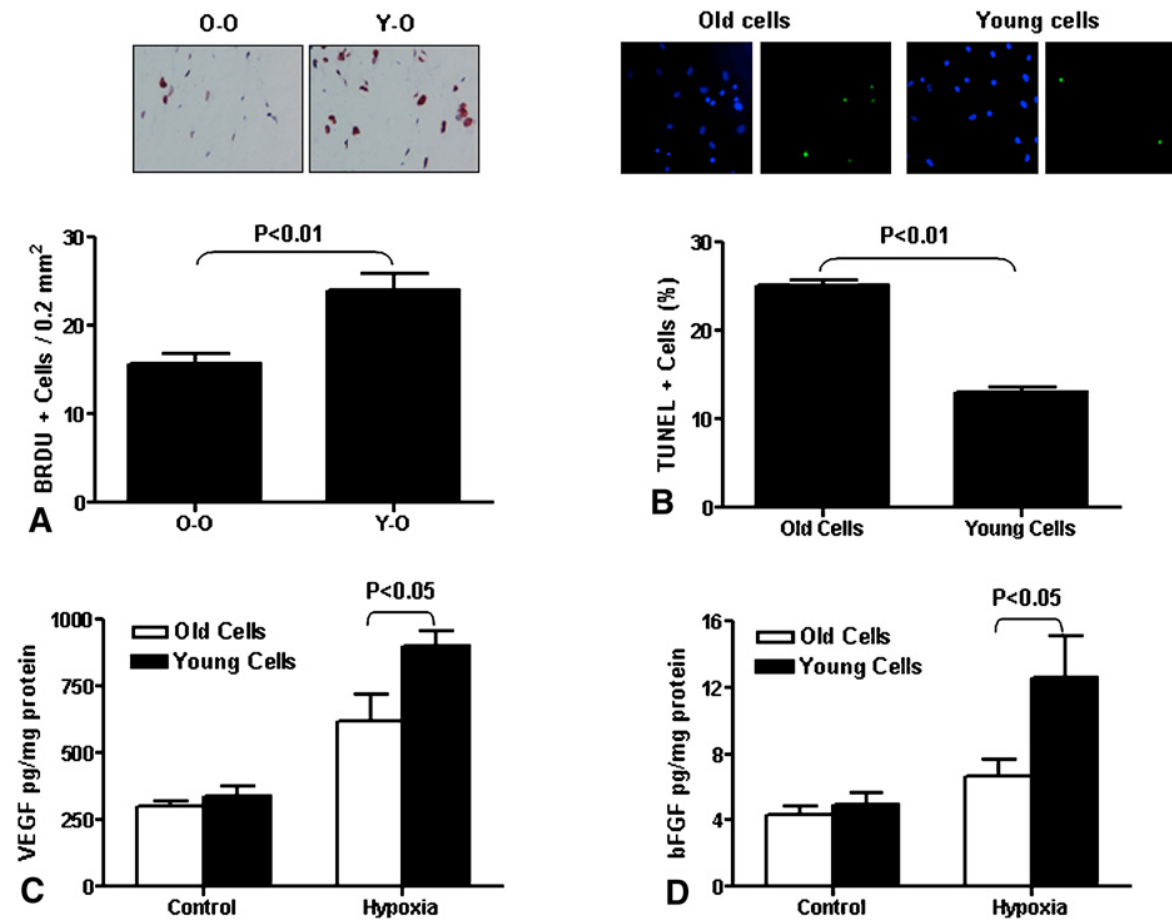

FIGURE 4. Factors contributing to the increased angiogenic potential of cells isolated from young donors. A, Representative micrographs (magnification $=$ $200 \times)$ illustrating bromodeoxyuridine $(\mathrm{BrdU})$ labeling (purple) in the ischemic hind limb muscle of old recipients of young $(\mathrm{Y}-\mathrm{O})$ or old $(\mathrm{O}-\mathrm{O})$ bone marrow stromal cells (BMSCs) prelabeled with BrdU, at 21 days after implantation; graph quantifying cell survival (BrdU+cells $/ 0.2 \mathrm{~mm}^{2} ; \mathrm{n}=10$ per group). B, Representative micrographs (magnification $=200 \times$ ) illustrating terminal dUTP nick-end labeling $(T U N E L)$ staining $($ green $=$ apoptotic cells; blue $=$ nuclei stained with 4,6-diamino-2-phenylindole) in BMSCs isolated from young or old rats (young cells; old cells) and cultured for 24 hours in hypoxic conditions (with serum-free medium); graph quantifying apoptosis (percent TUNEL+cells; $\mathrm{n}=6$ per group). $\mathrm{C}$ and $\mathrm{D}$, Levels of angiogenic cytokines (vascular endothelial growth factor $[V E G F], \mathrm{C}$; basic fibroblast growth factor $[b F G F], \mathrm{D})$ secreted by young cells and old cells after 24 hours culture in hypoxic conditions (with serum-free medium), and by age-matched controls $(\mathrm{n}=6$ per group).

$B)$ and greater numbers of EPCs in the blood and spleen (39\% and $31 \%$ higher, respectively; Figure $3, C$ and $D$ ) at 7 days after cell implantation in young compared with old recipients of BMSCs, despite similar significant increases in these measures relative to the respective age-matched medium recipients (all measures $P<.01$ ).

The blunted angiogenic response in old cell recipients was associated with decreased survival of the implanted young cells, inasmuch as significantly more BrdU-labeled BMSCs were identified in the ischemic tissue of young compared with old cell recipients (Y-Y: $31.45 \pm 2.22$; Y-O: $24.1 \pm$ 1.73 BrdU-positive cells per $0.2 \mathrm{~mm}^{2} ; P<.01$ ).

\section{The Combined Effects of Aging on Cell Recipients and Donor Cells Determine the Efficacy of} Angiogenic Cell Therapy

To evaluate the combined effects of aging on donor cells and recipients, we assessed (based on all groups studied) the statistical relationship between perfusion in the ischemic hind limb (LDPI at 21 days after cell transplantation) and the local production of angiogenic cytokines or EPC numbers in the recipient blood or spleen at 7 days after transplantation (Figure 5). All correlations were highly significant $\left(r^{2}>0.95\right.$ for all correlations; $\left.P<.001\right)$ and demonstrated linear relationships between LDPI and each of the variables.

As illustrated by the linear relationships in Figure 5, all cell recipients exhibited restoration of angiogenesis and perfusion in the ischemic hind limb; however, the relative degree of functional recovery varied among groups owing to the influence of age on the donor cells and the endogenous responses from the recipients. Not surprisingly, the greatest angiogenic response was in young recipients implanted with young donor cells. But interestingly, we found that the angiogenic response in old recipients implanted with young donor cells was similar to that in young recipients implanted with old donor cells. This suggests that donor cell age and recipient age may be equally important contributors to the outcome of cell therapy. A 2-way ANOVA confirmed significant $(P<.01)$ main effects of both donor cell age and recipient age. Finally, although improvements relative to age-matched medium controls were observed in old recipients implanted with old donor cells, LDPI in this group was significantly lower than that in the other groups that received cells and was similar to that in Y controls-an observation that also highlights the capacity for tissue repair in untreated young animals. The correlations in Figure 5 

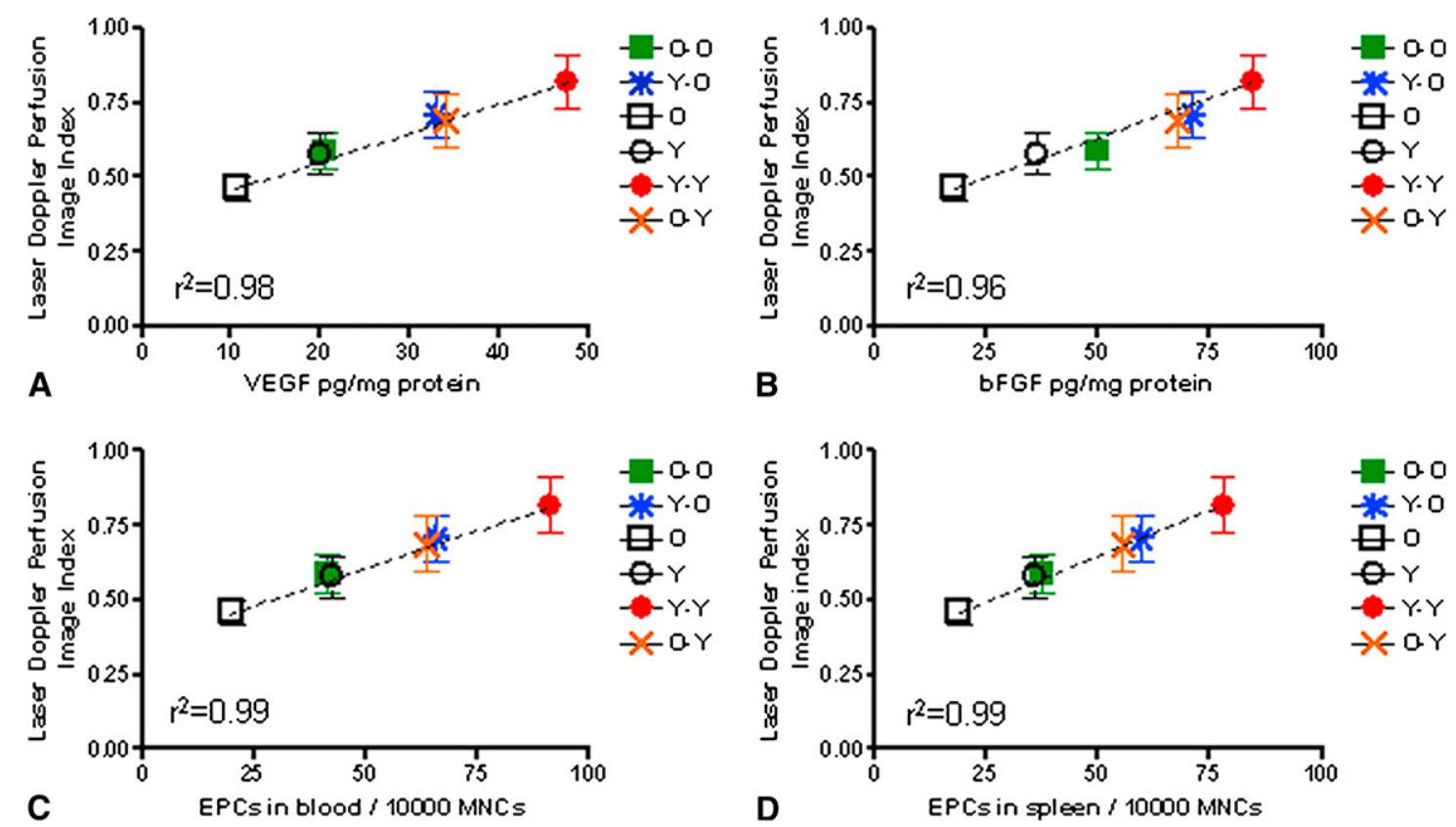

FIGURE 5. Correlating perfusion with the underlying factors: Group relationships (A-D). Significant linear correlations are illustrated between mean laser Doppler perfusion image (LDPI) index (at 21 days after cell implantation) and the following measures (all at 7 days after implantation): mean levels of vascular endothelial growth factor (VEGF; A) or basic fibroblast growth factor $(b F G F ; \mathrm{B})$ in the ischemic tissue; mean number of endothelial progenitor cells ( $E P C s$; per 10,000 mononuclear cells [MNCs]) in recipient blood (C) or spleen (D). All measurements were performed in the following groups: young or old recipients of culture medium only $(Y, O)$, young or old recipients of bone marrow stromal cells (BMSCs) isolated from young donors $(Y-Y, Y$ - $O)$, and young or old recipients of BMSCs isolated from old donors $(O-Y, O-O)$. All correlations were highly significant $(P<.001)$.

further suggest that differences in the secretion of angiogenic cytokines and the associated induction of endogenous stem cell homing and neovascularization might account for the range of functional outcomes among the different groups of cell recipients.

\section{DISCUSSION}

This study provides the first demonstration of the effects of aging (both separate and combined) on the response to ischemic injury and the activity of implanted cells in the context of cell therapy. We found that (1) old animals had a reduced capacity to respond to hind limb ischemia (and therefore, to subsequent cell therapy) by establishing a blood vessel network to restore perfusion, and (2) the implantation of aged (vs young) donor BMSCs induced less angiogenesis and more loss of muscle mass in ischemic recipients.

The mechanisms responsible for the age-related decline in the efficacy of cell therapy remain unclear, but studies of the aging process suggest numerous possibilities. ${ }^{9,16,17}$ Previous reports have established the limited ability of aged cells to secrete angiogenic factors and documented the limited capacity of older recipients to mobilize angiogenic progenitor cells, increase blood vessel density, or mitigate tissue loss after arterial ligation. ${ }^{10,18}$ However, the relative contributions of the limitations on these two components-cells and recipients—-have never been compared.
Several factors may account for the diminished effectiveness of old donor cells. First, cells isolated from old (vs young) donors have a reduced tolerance to ischemic injury, which could explain their decreased survival within ischemic muscle. The number of engrafted donor cells is known to correlate with the magnitude of improvement in perfusion, suggesting that reduced survival in old donor cells could limit perfusion and vessel formation by decreasing the overall biological stimulus exerted. In order to address this issue, implanted cell survival could be increased by transfecting the donor cells with survival factors before transplantation. ${ }^{20}$ Second, we found that BMSCs isolated from old donors produced less VEGF and bFGF than those isolated from young donors in response to ischemia, both in vitro and in vivo. Previous studies indicated that an age-related reduction in VEGF might limit the mobilization and survival or differentiation of EPCs. ${ }^{10}$ We showed here that a limited release of angiogenic factors by old donor cells was associated with fewer mobilized EPCs in the circulation and the spleen. The limitations imposed on donor cells by increased age could be addressed by rejuvenating donor cells from older patients before implantation or by using allogeneic cells as donors. $\mathrm{We}^{21,22}$ previously demonstrated that transfecting BMSCs with genes to enhance angiogenesis improved cell recruitment, and others have shown that healthy allogeneic BMSCs induced more angiogenesis in ischemic 
tissue than autologous cells from older individuals, ${ }^{23}$ although new strategies will be required to induce prolonged host tolerance of allogeneic cells.

A most important finding of this study is that the agediminished regenerative response of the recipient may be an equally important contributor to the limited benefit of cell therapy for older individuals. Young and old recipients of BMSCs isolated from young donors exhibited similar improvements in measures of angiogenesis relative to their respective, age-matched controls, suggesting a similar potential to respond to cell therapy. Therefore, the enhanced outcomes of cell therapy in the young (vs old) recipients were probably due to age-related differences in the regenerative response to the original ischemic injury, in which old animals fared worse than young. These unique observations have important therapeutic implications for older recipients of cell therapy. To achieve the full benefit of implanted cells, both the donor cells and the recipient will likely require new therapeutic interventions. Rejuvenating the regenerative capacity of older patients with multiple comorbidities (such as diabetes or diffuse atherosclerosis) may be necessary to boost angiogenesis. ${ }^{8}$ Bone marrow transplantation, which has been used to restore marrow function in malignant and benign diseases, could be used to renew marrow regenerative capacity in these patients. ${ }^{24}$ Also, both rejuvenated autologous and allogeneic donor cells have been evaluated clinically for their potential to enhance bone marrow function.

Our study is limited by the fact that we did not compare different cell doses, but instead used a single dose that was previously demonstrated effective in this model. ${ }^{1}$ As indicated, increasing the number of engrafted cells improves the response to cell therapy. ${ }^{19}$ In addition, we focused our assessment on the angiogenic response to ischemia or cell therapy and restricted our evaluation of the mechanisms responsible to measurements of growth factor secretion and EPC function. Although previous studies do suggest that neovascularization potential is profoundly reduced with aging, ${ }^{7,8}$ the outcome of cell therapy in this model is certainly determined by a combination of factors in addition to angiogenesis. However, now that we have established the equal contributions of age on donor cells and recipient responses, we anticipate that future investigations will provide more extensive assessments of the mechanisms involved and identify new therapeutic targets. New approaches might include, for example, inhibition of antiangiogenic mediators or activation of alternate growth factors in the angiogenic cascade.

The data presented here contribute to our understanding of the discrepancy between results from preclinical studies (performed in young animals), which demonstrated robust angiogenic and functional responses to cell therapy, and clinical trials (performed in older patients), which demonstrated only limited restorative responses. We conclude that the outcome of cell therapy in older recipients is determined by a combination of age effects on both donor cells and recipients. To enhance the clinical effectiveness of cell therapy for aged patients, future interventions should restore the regenerative capacities of both the implanted cells and the cell recipient.

\section{References}

1. Al-Khaldi A, Al-Sabti H, Galipeau J, Lachapelle K. Therapeutic angiogenesis using autologous bone marrow stromal cells: improved blood flow in a chronic limb ischemia model. Ann Thorac Surg. 2003;75:204-9.

2. Fazel S, Cimini M, Chen L, Li S, Angoulvant D, Fedak P, et al. Cardioprotective $\mathrm{c}$-kit + cells are from the bone marrow and regulate the myocardial balance of angiogenic cytokines. J Clin Invest. 2006;116:1865-77.

3. Kinnaird T, Stabile E, Burnett MS, Lee CW, Barr S, Fuchs S, et al. Marrowderived stromal cells express genes encoding a broad spectrum of arteriogenic cytokines and promote in vitro and in vivo arteriogenesis through paracrine mechanisms. Circ Res. 2004;94:678-85.

4. Tomita S, Mickle DA, Weisel RD, Jia ZQ, Tumiati LC, Allidina Y, et al Improved heart function with myogenesis and angiogenesis after autologous porcine bone marrow stromal cell transplantation. J Thorac Cardiovasc Surg. 2002;123:1132-40.

5. Schachinger V, Erbs S, Elsasser A, Haberbosch W, Hambrecht $R$, Holschermann $\mathrm{H}$, et al. Intracoronary bone marrow-derived progenitor cells in acute myocardial infarction. $N$ Engl J Med. 2006;355:1210-21.

6. Lipinski MJ, Biondi-Zoccai GG, Abbate A, Khianey R, Sheiban I, Bartunek J, et al. Impact of intracoronary cell therapy on left ventricular function in the setting of acute myocardial infarction: a collaborative systematic review and meta-analysis of controlled clinical trials. J Am Coll Cardiol. 2007;50:1761-7

7. Dimmeler S, Vasa-Nicotera M. Aging of progenitor cells: limitation for regenerative capacity? J Am Coll Cardiol. 2003;42:2081-2.

8. Heeschen C, Lehmann R, Honold J, Assmus B, Aicher A, Walter DH, et al. Profoundly reduced neovascularization capacity of bone marrow mononuclear cells derived from patients with chronic ischemic heart disease. Circulation. 2004 109:1615-22.

9. Rivard A, Fabre JE, Silver M, Chen D, Murohara T, Kearney M, et al. Age-dependent impairment of angiogenesis. Circulation. 1999;99:111-20.

10. Scheubel RJ, Zorn H, Silber RE, Kuss O, Morawietz H, Holtz J, et al. Age-dependent depression in circulating endothelial progenitor cells in patients undergoing coronary artery bypass grafting. J Am Coll Cardiol. 2003;42:2073-80.

11. Edelberg JM, Tang L, Hattori K, Lyden D, Rafii S. Young adult bone marrow-derived endothelial precursor cells restore aging-impaired cardiac angiogenic function. Circ Res. 2002;90:E89-93.

12. Rauscher FM, Goldschmidt-Clermont PJ, Davis BH, Wang T, Gregg D, Ramaswami P, et al. Aging, progenitor cell exhaustion, and atherosclerosis. Circulation. 2003;108:457-63.

13. Conboy IM, Conboy MJ, Wagers AJ, Girma ER, Weissman IL, Rando TA. Rejuvenation of aged progenitor cells by exposure to a young systemic environment Nature. 2005;433:760-4.

14. Takahashi T, Kalka C, Masuda H, Chen D, Silver M, Kearney M, et al. Ischemiaand cytokine-induced mobilization of bone marrow-derived endothelial progenitor cells for neovascularization. Nat Med. 1999;5:434-8.

15. Urbich C, Dimmeler S. Endothelial progenitor cells: characterization and role in vascular biology. Circ Res. 2004;95:343-53.

16. Ryan NA, Zwetsloot KA, Westerkamp LM, Hickner RC, Pofahl WE, Gavin TP. Lower skeletal muscle capillarization and VEGF expression in aged vs. young men. J Appl Physiol. 2006;100:178-85.

17. Wagatsuma A. Effect of aging on expression of angiogenesis-related factors in mouse skeletal muscle. Exp Gerontol. 2006;41:49-54

18. Gennaro G, Menard C, Michaud SE, Rivard A. Age-dependent impairment of reendothelialization after arterial injury: role of vascular endothelial growth factor. Circulation. 2003;107:230-3.

19. Pouzet B, Vilquin JT, Hagege AA, Scorsin M, Messas E, Fiszman M, et al. Factors affecting functional outcome after autologous skeletal myoblast transplantation. Ann Thorac Surg. 2001;71:844-50.

20. Nakamura Y, Yasuda T, Weisel RD, Li RK. Enhanced cell transplantation: preventing apoptosis increases cell survival and ventricular function. Am J Physiol Heart Circ Physiol. 2006;291:H939-47. 
21. Fazel S, Chen L, Weisel RD, Angoulvant D, Seneviratne C, Fazel A, et al. Cell transplantation preserves cardiac function after infarction by infarct stabilization: augmentation by stem cell factor. J Thorac Cardiovasc Surg. 2005;130:1310.

22. Kim C, Li RK, Li G, Zhang Y, Weisel RD, Yau TM. Effects of cell-based angiogenic gene therapy at 6 months: persistent angiogenesis and absence of oncogenicity. Ann Thorac Surg. 2007;83:640-6.
23. Amado LC, Saliaris AP, Schuleri KH, St John M, Xie JS, Cattaneo S, et al. Cardiac repair with intramyocardial injection of allogeneic mesenchymal stem cells after myocardial infarction. Proc Natl Acad Sci U S A. 2005;102: 11474-9.

24. Sykes M, Nikolic B. Treatment of severe autoimmune disease by stem-cell transplantation. Nature. 2005;435:620-7. 


\section{E-MATERIALS AND METHODS}

\section{Isolation and Expansion of BMSCs}

BMSCs were obtained by flushing the cavities of tibias and femurs from young or old rats as described previously, ${ }^{\mathrm{E} 1}$ cultured in Iscove's modified Dulbecco's medium (Gibco; Invitrogen Corporation, Carlsbad, Calif) with $10 \%$ fetal bovine serum, $100 \mathrm{U} / \mathrm{mL}$ penicillin $\mathrm{G}$, and $100 \mu \mathrm{g} / \mathrm{mL}$ streptomycin, and placed into a humidified incubator at $37^{\circ} \mathrm{C}$ with $5 \%$ carbon dioxide. After 3 to 5 days, nonadherent hematopoietic cells were washed away. Adherent BMSCs were expanded (3 passages) for transplantation.

\section{Characterization of BMSCs}

BMSCs were characterized by flow cytometry with various cell surface markers. ${ }^{\text {E2 }}$ In brief, the adherent cells were detached with a cell dissociation solution according to the manufacturer's instructions (Sigma), and $1 \times 10^{6}$ cells were stained for phycoerythrin-conjugated anti-CD90.1 (eBiosciences, San Diego, Calif) and fluorescein isothiocyanate (FITC)-conjugated antiCD29, -CD45, -CD117, and -CD34 (BD Pharmingen, San Diego, Calif). Rat IgG isotype control antibodies (BD Pharmingen) were used as controls. All antibody incubations were carried out for 30 minutes at $4^{\circ} \mathrm{C}$ in the dark. Cells were analyzed by a Beckman Coulter EPICS XL flow cytometer with EXPO32 ADC software (Beckman Coulter, Fullerton, Calif). The fluorescence intensity of 10,000 cells per sample was quantified.

\section{Hind Limb Ischemia Model}

The rat hind limb ischemia model was established previously. ${ }^{\text {E3 }}$ In brief, young (6-8 weeks old) and old (60-64 weeks old) rats were anesthetized in an isoflurane chamber and then intubated and maintained with inhaled isoflurane $(1 \%-2 \%)$ during the operation. To establish unilateral hind limb ischemia in each animal, the right common iliac artery, the promixal portion of the right femoral artery, and the distal portion of the saphenous artery were ligated with 5-0 silk and excised. Left hind limbs were left intact as nonischemic controls.

\section{Hind Limb Blood Perfusion}

Blood perfusion in the hind limbs was measured with an LDPI analyzer (PeriScan PIM 3 Systems) at 5 time points: before the operation at day 0 to establish hind limb ischemia; immediately before cell transplantation at 1 day after ischemia; and 7, 14, and 21 days after transplantation. The perfusion signal was subdivided into 6 different intervals, each displayed as a separate color, with low or no perfusion displayed as dark blue and highest perfusion displayed as red. Before scanning was initiated, excess hind limb hair was removed with a shaver, and each rat was placed on a $37^{\circ} \mathrm{C}$ heating plate for 15 to 20 minutes. After blood flow was scanned twice in each region of interest (legs and feet), average flow values for ischemic and nonischemic hind limbs were calculated by computer-assisted quantification of the stored images. To minimize variations due to ambient light and temperature, we calculated an LDPI index as the ratio of ischemic to nonischemic hind limb perfusion. ${ }^{\mathrm{E} 4}$

\section{Capillary and Arteriolar Densities in Ischemic Tissue}

At 21 days after transplantation, capillary densities and arteriolar densities were quantified in the ischemic hind limb muscles ( $n=4$ per group). So that capillary densities could be assessed, the right adductor and semimembranous muscles were embedded in Tissue-Tek OCT compound (Sakura Finetek, Torrance, Calif) and then snap-frozen in liquid nitrogen. Transverse sections ( $5 \mu \mathrm{m}$ thick) were stained with alkaline phosphatase and counterstained with eosin. Under light microscopy (Nikon, Tokyo, Japan), capillaries were counted in 5 randomly selected, high-power fields per section by 2 different investigators blinded to the study conditions. So that overestimating or underestimating the number of capillaries due to myocyte atrophy or interstitial edema could be avoided, capillary density was expressed as the ratio of capillaries/muscle fibers.
Arteriolar densities were assessed by immunostaining serial cryosections with an FITC-conjugated anti- $\alpha$-smooth muscle actin antibody, and staining the nuclei with 4',6-diamidino-2-phenylindole. The average number of FITC-positive arteriole rings per high-power field was quantified with a $\mathrm{Ni}$ kon fluorescent microscope.

\section{In Vitro Donor Cell Apoptosis}

BMSCs $\left(3 \times 10^{5}\right)$ isolated from young $(n=6)$ or old $(n=6)$ donor rats were cultured in 24-well plates, in a hypoxic environment with serum-free medium for 24 hours, and subsequently fixed in $2 \%$ paraformaldehyde for 10 minutes. Apoptotic cells were detected by a TUNEL assay, according to the manufacturer's instructions, and nuclei were stained with 4',6-diamidino-2-phenylindole (Sigma). TUNEL-positive cells were counted in 3 randomly selected fields per well by 2 different investigators blinded to the study conditions. Counts were expressed as the percent of apoptotic cells (TUNEL-positive cells/total cells).

\section{In Vivo Implanted Cell Survival}

Donor BMSCs were labeled with $10 \mu \mathrm{mol} / \mathrm{L} \mathrm{BrdU}$ for 24 hours, and then implanted into ischemic muscle tissue. Thigh muscles were harvested $(\mathrm{n}=$ 10 per group) at 21 days after transplantation and fixed with $10 \%$ formaldehyde formalin. The fixed tissues were cut into 2 -mm thick slices, embedded in paraffin, and sectioned for histologic studies. So that the implanted BMSCs could be identified, sections were immunostained with a monoclonal antibody against BrdU (Caltag Laboratories, Camarillo, Calif). Implanted cell survival in the ischemic tissue was quantified in 5 randomly selected fields from each section and expressed as the average number of BrdU-positive nuclei per $0.2 \mathrm{~mm}^{2}$.

\section{In Vitro and In Vivo VEGF and bFGF Protein Expression}

So that the secretion of angiogenic factors in BMSCs isolated from young and old rats could be compared, $3 \times 10^{5}$ BMSCs from young and old donors ( $\mathrm{n}=6$ per group) were cultured in 24-well plates with serumfree medium for 24 hours or incubated in a hypoxic environment with serum-free medium for 24 hours. The conditioned medium was collected, and VEGF and bFGF expression levels were measured with ELISA kits (Quantikine; R\&D Systems).

So that VEGF and bFGF protein expression in the ischemic hind limbs could be determined, muscle samples ( $n=6$ per group) were harvested at 7 days after cell transplantation and homogenized in liquid nitrogen. Total protein was extracted from $100 \mathrm{mg}$ of powdered tissue in lysis buffer $(20$ $\mathrm{mmol} / \mathrm{L}$ Tris [pH 7.4], $150 \mathrm{mmol} / \mathrm{L} \mathrm{NaCl}, 1 \mathrm{mmol} / \mathrm{L}$ ethylenediaminetetraacetic acid, $1 \mathrm{mmol} / \mathrm{L}$ ethyleneglycol-bis-( $\beta$-aminoethylether)-N,N, $\mathrm{N}^{\prime} \mathrm{N}^{\prime}$ tetraacetic acid, $1 \%$ Triton, $2.5 \mathrm{mmol} / \mathrm{L} \mathrm{Na}$ pyrophosphate, $1 \mathrm{mmol} / \mathrm{L} \beta$ glycerolphosphate, $1 \mathrm{mmol} / \mathrm{L}$ vanadate $\left(\mathrm{Na}_{3} \mathrm{VO}_{4}\right), 1 \mu \mathrm{g} / \mathrm{mL}$ leupeptin, 1 $\mu \mathrm{g} / \mathrm{mL}$ pepstatin, and $1 \mathrm{mmol} / \mathrm{L}$ phenylmethylsulfonyl fluoride) for 1 hour on ice. After centrifugation at $10,000 \mathrm{~g}$ for 10 minutes, the supernatant was collected, and protein concentration was determined with a Bio-Rad DC protein assay kit according to the manufacturer's instructions. VEGF and bFGF expression were measured with ELISA kits and normalized by picograms per milligram of total protein.

\section{EPC Mobilization}

So that EPC mobilization from the bone marrow could be assessed after the induction of hind limb ischemia, EPC-like mononuclear cells were quantified in both peripheral blood and spleen. At 7 days after transplantation in young and old rats (and before ischemia in $\mathrm{Y}$ control and $\mathrm{O}$ control; $\mathrm{n}=5$ per group), EPC-like mononuclear cells were isolated from blood $(1 \mathrm{~mL})$ and spleen by centrifugation through a Histopaque-1083 density gradient (Sigma) and then incubated on ice for 40 minutes with an FITC-conjugated anti-human CD34 antibody (Caltag) and a phycoerythrin-conjugated anti-human KDR antibody (R\&D Systems). The cells were washed twice with phosphate-buffered 
saline containing $2 \%$ fetal bovine serum and $0.1 \%$ sodium azide, and EPCs were identified by flow cytometry as $\mathrm{CD} 34^{+} / \mathrm{KDR}^{+}$cells. ${ }^{\mathrm{E} 5 \mathrm{E} 6}$

\section{E-References}

E1. Rochester JR, Brown NJ, Reed MW. Characterisation of an experimental model of chronic lower limb ischaemia in the anaesthetised rat. Int J Microcirc Clin Exp. 1994;14:27-33.

E2. Murohara T, Ikeda H, Duan J, Shintani S, Sasaki K, Eguchi H, et al. Transplanted cord blood-derived endothelial precursor cells augment postnatal neovascularization. J Clin Invest. 2000;105:1527-36.
E3. Shintani S, Murohara T, Ikeda H, Ueno T, Sasaki K, Duan J, et al. Augmentation of postnatal neovascularization with autologous bone marrow transplantation. Circulation. 2001;103:897-903.

E4. Atluri P, Liao GP, Panlilio CM, Hsu VM, Leskowitz MJ, Morine KJ, et al. Neovasculogenic therapy to augment perfusion and preserve viability in ischemic cardiomyopathy. Ann Thorac Surg. 2006;81:1728-36.

E5. Takahashi T, Kalka C, Masuda H, Chen D, Silver M, Kearney M, et al. Ischemiaand cytokine-induced mobilization of bone marrow-derived endothelial progenitor cells for neovascularization. Nat Med. 1999;5:434-8.

E6. Urbich C, Dimmeler S. Endothelial progenitor cells: characterization and role in vascular biology. Circ Res. 2004;95:343-53. 